\title{
Distribuição Horizontal e Taxas de Crescimento, Senescência e Desfolhação de Azevém Perene e Festuca, Puros e em Associação 1
}

\author{
Andréa Machado Groff ${ }^{2}$, Jean-François Soussana ${ }^{3}$, Frédérique Louault ${ }^{3}$, Anibal de Moraes ${ }^{4}$, \\ Edson Cristiano Groff ${ }^{5}$
}

\begin{abstract}
RESUMO - O experimento foi realizado no INRA (Institut National de la Recherche Agronomique) em Theix, França. Duas gramíneas (azevém perene e festuca) foram semeadas em caixas $\left(0,13 \mathrm{~m}^{2}\right)$ usando-se três distribuições horizontais do pasto (pura, linhas alternadas e faixas alternadas) e três intervalos de desfolhações (3,5, 7 e 14 dias), com quatro repetições por tratamento. Quatro meses após a semeadura, a cada data de desfolhação, as caixas foram oferecidas, individualmente, a quatro ovelhas secas e retiradas após a realização de 340 bocados. $\mathrm{m}^{-2}$. Para cada gramínea estudaram-se a densidade populacional e a massa de perfilhos, a altura e a produção de matéria seca, a profundidade e a massa do bocado e as taxas de crescimento, senescência e desfolhação. A maior altura do pasto, gerada por desfolhações menos freqüentes, promoveu a realização de bocados mais profundos e de maior massa. Por outro lado, em desfolhações mais freqüentes a altura do pasto foi mantida mais baixa, e a profundidade e massa do bocado foram menores. A distribuição horizontal das plantas promoveu respostas diferenciadas em relação as taxas de crescimento, senescência e desfolhação. Quando em linhas alternadas a festuca teve a taxa de crescimento limitada, provavelmente desfavorecida pela competição.
\end{abstract}

Palavras-chave: competição, Festuca arundinacea, Lolium perenne, massa do bocado, profundidade do bocado, seleção

\section{Horizontal Distribution and Growth, Senescence and Defoliation Fluxes of Perennial Ryegrass and Tall Fescue Pure and Mixed Swards}

\begin{abstract}
The experiment was carried in INRA (Institut National de la Recherche Agronomique) at Theix, France. Two grasses (perennial ryegrass and tall fescue) were grown in sward boxes $\left(0,13 \mathrm{~m}^{2}\right)$, using three different sward horizontal distribution (pure, alternate rows and alternate strips) and three defoliation intervals (3,5, 7 and 14 days between two successive defoliation) with four replications. Four months after sowing, at defoliation date, sward boxes were offered to four individual dry ewes and removed after 340 bites. $\mathrm{m}^{-2}$ had been taken. For each grass species, the population density and the tiller mass, sward height, herbage production, bite depth and bite mass and growth, senescence and defoliation fluxes were studied. Taller swards generated by less frequent defoliation, resulted in larger numbers for bite depth and size than for shorter. On the other hand, under more frequent defoliation, sward height was maintained lower, and bite and size were smaller. The horizontal distribution of the sward resulted in different responses in relation to the growth, senescence and defoliation fluxes. In alternate row arrangement, tall fescue probably had the growth flux limited by interspecific competition.
\end{abstract}

Key Words: competition, Festuca arundinacea, Lolium perenne, bite mass, bite depth, selectivity

\section{Introdução}

A associação de espécies tem sido uma alternativa utilizada para melhorar a distribuição da produção do pasto ao longo do ano e a qualidade da dieta dos animais. No entanto, esse é um sistema de maior complexidade, onde fatores como a competição entre plantas e a seleção animal atuam dificultando a manutenção do equilíbrio entre espécies.

A competição que ocorre entre plantas depende da forma de utilização dos recursos (água, luze nutrientes).
Além disso, o equilíbrio de espécies associadas pode evoluir também em função das necessidades de cada espécie. Determinadas plantas utilizam como estratégia colocar suas folhas nos estratos superiores, afim de otimizar o uso da luminosidade mas, no entanto, essa estratégia as deixa mais vulneráveis à desfolhação (Briske, 1991). Já a seleção efetuada pelo animal depende, dentre outros fatores, das distribuições vertical e horizontal do pasto e da preferência (Carvalho, 1997).

O processo de desfolhação pode ser caracterizado

\footnotetext{
${ }^{1}$ Parte da tese de doutorado da primeira autora.

2 Eng.-Agrônoma, aluna de doutorado da UFPR/Curitiba. Bolsista da CAPES. Rua Pedro Fabri, 34, CEP 80035-250. Curitiba - PR. E.mail: andrea_groff@yahoo.com.br

3 Pesquisadores do Institut National de la Recherche Agronomique (INRA) - Clermont Ferrand - França.

4 Professor Adjunto do Departamento de Fitotecnia e Fitossanitarismo da UFPR.

${ }^{5}$ Estudante do curso de Agronomia da UFPR.
} 
como um dos fatores determinantes das modificações estruturais do pasto, por meio da redução da superfície foliar e, eventualmente, do número de pontos de crescimento, diminuindo assim a produção de matéria seca (MS) (Mazzanti, 1997).

A resposta das plantas à desfolhação depende, dentre outros fatores, da velocidade de emissão de folhas, uma vez que espécies com velocidade de emissão de folhas mais rápida são mais adaptadas à desfolhações mais freqüentes (Lemaire \& Chapman, 1996; Lemaire, 1999).

Dessa forma, a interação da resposta das espécies à desfolhação e dos componentes da desfolhação (intervalo e intensidade) determinam o funcionamento do dossel e o equilíbrio entre espécies.

Para se estudar a resposta das plantas em associação aos componentes da desfolhação (intervalo e intensidade), utilizou-se uma espécie de velocidade rápida de emissão de folhas e de maior palatabilidade (azevém perene) associada a outra de menor velocidade de emissão de folhas e menor palatabilidade (festuca). A partir disso foram testadas as seguintes hipóteses:

a) se a velocidade de emissão de folhas determina a resposta à desfolhação, então a espécie com velocidade mais rápida de emissão de folhas se adaptará melhor a condições de desfolhação frequiente, pois pode renovar suas folhas mais rapidamente;

b) se o processo de desfolhação é influenciado pela distribuição horizontal das plantas e pela seleção animal, então a variação na distribuição horizontal do pasto modificará a competição entre plantas e o processo de seleção levando a taxas de crescimento, desfolhação e senescência diferenciadas.

Sendo assim, o presente estudo teve como objetivo geral avaliar os efeitos da distribuição horizontal sobre as taxas de crescimento, senescência e desfolhação do azevém perene e da festuca e como objetivo específico estudar a desfolhação do azevém perene e da festuca, por meio da massa e profundidade de bocados, em pastos mantidos baixos, altos e em condição intermediária por meio de diferentes intervalos de desfolhação impostos sobre os pastos de azevém perene e festuca, semeados de acordo com três tipos de distribuição horizontal (pura, linhas alternadas e faixas alternadas).

\section{Material e Métodos}

\section{Estabelecimento}

O experimento foi realizado na Fazenda Experimental do INRA (Institut National de la Recherche Agronomique) em Theix, França. O clima é classificado como semi-continental, com precipitação média anual de $760 \mathrm{~mm}$ e temperatura média diária variando de 1 a $20^{\circ} \mathrm{C}$ no período de janeiro a agosto (Louault et al., 1997).

Em janeiro de 1999, a associação de azevém perene (Lolium perenne cv. Fennema) e festuca (Festuca arundinacea cv. Clarine, livre de fungo endofítico), foi semeada em caixas de $0,39 \times 0,33 \mathrm{~m}$ $\left(0,13 \mathrm{~m}^{2}\right)$ e $0,14 \mathrm{~m}$ de profundidade. Essas espécies foram escolhidas por possuírem velocidade de emissão de folhas e palatabilidade diferentes, sendo o azevém perene de maior palatabilidade e velocidade de emissão de folhas quando comparado à festuca.

As gramíneas foram estabelecidas em oito linhas separadas de $5 \mathrm{~cm}$ com o uso de 41 e $76 \mathrm{~kg}$ de sementes.ha ${ }^{-1}$ para o azevém perene e festuca, respectivamente. Como substrato utilizou-se terra, que

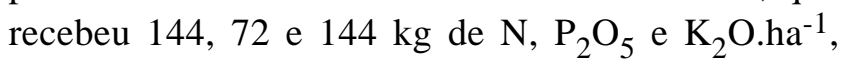
respectivamente, usando o adubo formulado 16-8-16.

O tratamento de linhas alternadas foi composto por uma linha de azevém e uma linha de festuca dispostas alternadamente totalizando quatro linhas por espécie. Essa distribuição permitiu que as espécies estivessem bem misturadas, dificultando a seleção. Já em faixas alternadas, quatro linhas de festuca e quatro de azevém foram semeadas lado a lado de forma a facilitar o processo de seleção.

Durante a fase de estabelecimento (quatro meses), as caixas foram mantidas em casa de vegetação e a cada duas semanas as gramíneas foram cortadas a $5 \mathrm{~cm}$ de altura afim de estimular o perfilhamento. Além disso, no período do estabelecimento e posteriormente durante toda a fase experimental, duas vezes por semana, as caixas foram irrigadas e, a cada 15 dias, adubadas com $50 \mathrm{~kg}$ de N.ha-1, sendo aplicado como fonte de nitrogênio o nitrato de amônio.

\section{Modelo experimental}

O delineamento experimental utilizado foi o de blocos completos ao acaso. Os tratamentos foram compostos por três distribuições horizontais (pura, linhas alternadas e faixas alternadas) e três intervalos de desfolhação (3,5, 7 e 14 dias), com quatro repetições por tratamento. 


\section{Animais}

Foram utilizadas quatro ovelhas secas da raça INRA 401, com largura média de arcada dentária de $3,5 \pm 0,2 \mathrm{~cm}$ e peso vivo médio de $60 \pm 9,3 \mathrm{~kg}$. Essas foram primeiramente selecionadas de um lote de 14 , e treinadas a pastejar as caixas durante um período de duas semanas. Os animais foram mantidos em baias individuais e receberam pela manhã (após a desfolhação das caixas), feno de aveia $(0,8 \mathrm{~kg})$, grãos de cevada $(0,2 \mathrm{~kg})$ e palha de trigo à vontade.

\section{Desfolhação}

A cada data de desfolhação as caixas foram oferecidas, pela manhã, separadamente a cada ovelha, sendo colocadas sobre um suporte de madeira afim de permitir que a caixa e o piso das baias, onde os animais eram mantidos, ficassem no mesmo nível (como em condições de campo). Após a realização de 340 bocados. $\mathrm{m}^{-2}$, contados visualmente por duas pessoas, as caixas eram removidas. Para o cálculo da profundidade média do bocado, antes e após cada desfolhação, a altura de cada espécie foi medida (sward stick) tomando-se 32 pontos por tratamento. Posteriormente, as caixas foram pesadas em balança de precisão $( \pm 1 \mathrm{~g})$ e amostradas 24 folhas (última folha adulta ou outra folha adulta em bom estado) de cada espécie por tratamento. Em seguida, esse material foi seco $\left(48\right.$ horas a $\left.70^{\circ} \mathrm{C}\right)$, pesado em balança analítica $(0,0001 \mathrm{~g})$ e os teores de MS determinados.

A partir desses dados foi efetuado o cálculo da massa do bocado dividindo-se o consumopor caixa (emg deMS) pelo número médio de bocados realizados em cada caixa e a profundidade média do bocado $(\mathrm{cm})$, calculada pela diferença de altura antes e após desfolhação.

\section{Características do pasto}

Para a determinação das características do pasto, no início e no final do experimento, foram amostradas quatro caixas por tratamento cortando-se (no nível do solo), para cada espécie, quatro segmentos de linha de $2 \mathrm{~cm}$ de comprimento. Posteriormente, em laboratório, o número de perfilhos foi contado, o material pesado, seco em estufa $\left(48\right.$ horas a $70^{\circ} \mathrm{C}$ ) e determinadas a produção de MS, a porcentagem de festuca na MS, a densidade populacional de perfilhos e a massa de perfilhos individuais.

Taxa de crescimento, senescência e desfolhação

As medições das taxas de crescimento, senescência e desfolhação foram realizadas durante três semanas, somente no intervalo de pastejo de sete dias. Foram marcados (com um fio colorido preso ao solo por um prego) 24 perfilhos (6 por caixa) por espécie e por tratamento. A cada desfolhação (antes e após) foram medidos (em $\mathrm{mm}$ ) o comprimento verde e o comprimento senescente de lâminas, o comprimento da bainha e de perfilhos não adultos (com menos de duas folhas adultas).

As taxas de crescimento, senescência e desfolhação foram calculadas de acordo com Carrère et al. (1997).

A eficiência real de utilização do pasto (ERUP) foi calculada relacionando-se as taxas de desfolhação (D) e crescimento do pasto $(\mathrm{C})$, ou seja: ERUP $=\mathrm{D} / \mathrm{C}$. A eficiência potencial de utilização do pasto (EPUP) foi obtida pela fórmula: $\mathrm{EPUP}=1-\mathrm{S} / \mathrm{C}$, em que $\mathrm{S}$ representa a taxa de senescência do pasto (Louault et al., 1997).

Com o objetivo de avaliar a seleção entre espécies durante a desfolhação, o tratamento com a distribuição horizontal de faixas alternadas foi filmado e, posteriormente, o número de bocados realizados em cada espécie contado por dois observadores.

Intervalo real de desfolhação do perfilho

O intervalo real de desfolhação do perfilho foi calculado dividindo-se o intervalo de desfolhação (dias) pela probabilidade de desfolhação do perfilho. A probabilidade de desfolhação do perfilho foi calculada como sendo a relação entre o número de perfilhos marcados que foram desfolhados e o número total de perfilhos marcados.

Cálculo do índice de agressividade do azevém

O grau de competição da associação das gramíneas foi comparado por meio dos valores médios do índice de agressividade (IA) calculado pela fórmula proposta por McGilhirst \& Trenbath (1971):

$$
I A=0,5\left(\frac{M A_{F}}{M A}-\frac{M F_{A}}{M F}\right)
$$

em que MAF e MFA são, respectivamente, a produção de MS do azevém e da festuca quando associados e MA e MF, a produção de azevém e festuca, respectivamente, quando puros.

\section{Análise estatística}

Os dados foram submetidos à análise de variância usando-se o programa Statgraphics Plus Versão 4.1 (USA). Para a análise de variância utilizou-se a média dos dados por caixa com os fatores intervalo de desfolhação, distribuição horizontal do pasto, espécie, animal e suas interações. Para a comparação de médias foi adotado o teste de Tukey a 5\% de probabilidade. 


\section{Resultados e Discussão}

Características do pasto no início do experimento

No início do experimento a densidade populacional de perfilhos e a produção de MS para as duas espécies foram maiores para pastos puros, relativamente à distribuição em linhas alternadas e faixas alternadas (Tabela 1).

Comparando-se as espécies com relação a densidade populacional de perfilhos (Tabela 1) é observado que o azevém, nas três distribuições horizontais apresentou uma maior densidade populacional de perfilhos que a festuca.

Para a massa do perfilho (Tabela 1) os resultados foram semelhantes entre espécies, exceto para o tratamento de linhas alternadas, onde os perfilhos de festuca apresentaram uma menor massa. Nessas condições, a festuca teve um menor número de perfilhos provavelmente devido ao maior índice de agressividade do azevém (Tabela 1). No entanto, quando associada em faixas alternadas isto não ocorreu, pois nessa condição oíndice de agressividade do azevém foi praticamente nulo, indicando que a competição entre espécies foi pequena. Com relação à produção de MS, não houve diferença entre as espécies.

Com relação à porcentagem de festuca na associação (Tabela 1), no início do experimento, essa manteve-se em 14 e $44 \%$, respectivamente, nas distribuições horizontais de linhas alternadas e faixas alternadas.

\section{Altura dos pastos}

A diferença de altura entre o azevém perene e a festuca, após a estabilização do dossel (final do experimento) foi maior para os intervalos de desfolhação de 7 e 14 dias (Figura 1). Nessa situação, quando pura, a festuca manteve-se mais alta que o azevém. No entanto, quando em associação, apresentou-se mais baixa, provavelmente desfavorecida pela competição com o azevém.

A diminuição do intervalo de desfolhação reduziu $(\mathrm{p}<0,05)$ a altura do pasto, uma vez que desfolhações mais freqüentes removem maior quantidade de material. A maior remoção de material ocorre em função da profundidade do bocado, pois pastos mantidos mais altos permitem a realização de bocados mais profundos e, conseqüentemente, de maior massa (Carvalho, 1997).

\section{Profundidade e massa do bocado}

A profundidade do bocado é uma variável diretamente relacionada à altura do pasto. Em geral, os dosséis mais altos permitem a realização de bocados de maior profundidade (Wade, 1991; Illius et al., 1992; Gordon \& Lascano, 1993). Sendo assim, o menor intervalo de desfolhação reduziu a altura do pasto e, conseqüentemente, resultou em menor profundidade do bocado (Figura 2).

A profundidade do bocado foi maior (Figura 2) para a festuca na distribuição horizontal pura quando comparada às associações, o que indica que nessas condições a intensidade de desfolhação dessa espécie

Tabela 1 - Características do azevém perene $(A)$ e da festuca $(F)$, no início do experimento, em função da distribuição horizontal do pasto: pura ( $P$ ), linhas alternadas (LA) e faixas alternadas (FA)

Table 1 - Initial sward characteristics of perennial ryegrass $(R)$ and tall fescue $(F)$, in different sward horizontal distribution: pure $(P)$, alternate rows $(A R)$ and alternate strips $(A S)$

\begin{tabular}{|c|c|c|c|c|}
\hline & \multirow[t]{2}{*}{$\begin{array}{l}\text { Espécie } \\
\text { Specie }\end{array}$} & \multicolumn{3}{|c|}{$\begin{array}{c}\text { Distribuição horizontal } \\
\text { Horizontal distribution }\end{array}$} \\
\hline & & $\begin{array}{l}\mathrm{P} \\
P\end{array}$ & $\begin{array}{l}\mathrm{LA} \\
A R\end{array}$ & $\begin{array}{l}\text { FA } \\
A S\end{array}$ \\
\hline Densidade populacional (perfilhos. $\mathrm{m}^{-1}$ ) & $\mathrm{A}(R)$ & $1538 \mathrm{Aa}$ & $959^{\mathrm{Ab}}$ & $606^{\mathrm{Ac}}$ \\
\hline Populaton density (tillers. $\left.\mathrm{m}^{-1}\right)$ & $\mathrm{F}(F)$ & $975^{\mathrm{Ba}}$ & $219^{\mathrm{Bb}}$ & $409^{\mathrm{Bb}}$ \\
\hline Massa do perfilho (g de MS) & $\mathrm{A}(R)$ & $0,024^{\mathrm{Aa}}$ & $0,038^{\mathrm{Aa}}$ & $0,042^{\mathrm{Aa}}$ \\
\hline Tiller mass ( $g$ DM) & $\mathrm{F}(F)$ & $0,046^{\mathrm{Aa}}$ & $0,026^{\mathrm{Ba}}$ & $0,040^{\mathrm{Aa}}$ \\
\hline Produção de forragem (g de MS.m $\left.{ }^{-1}\right)$ & $\mathrm{A}(R)$ & $38^{\mathrm{Aa}}$ & $36^{\mathrm{Bb}}$ & $21^{\mathrm{Ab}}$ \\
\hline Herbage yield $\left(\mathrm{g} D M . \mathrm{m}^{-1}\right)$ & $\mathrm{F}(F)$ & $43^{\mathrm{Aa}}$ & $6^{\mathrm{Bb}}$ & $17^{\mathrm{Ab}}$ \\
\hline $\begin{array}{l}\text { Índice de agressividade do azevém } \\
\text { Ryegrass agressivity index }\end{array}$ & - & - & $0,41^{\mathrm{a}}$ & $0,09^{\mathrm{b}}$ \\
\hline $\begin{array}{l}\text { Festuca }(\%) \\
\text { Tall fescue }(\%)\end{array}$ & - & - & 14 & 44 \\
\hline
\end{tabular}

Médias seguidas de letras distintas (maiúsculas nas colunas e minúsculas nas linhas) diferem $(p<0,05)$ pelo teste Tukey. Means with different letters (high cap columnwise and low cap rowwise) differ significantly at $p<.05$ according to Tukey multiple range test. 


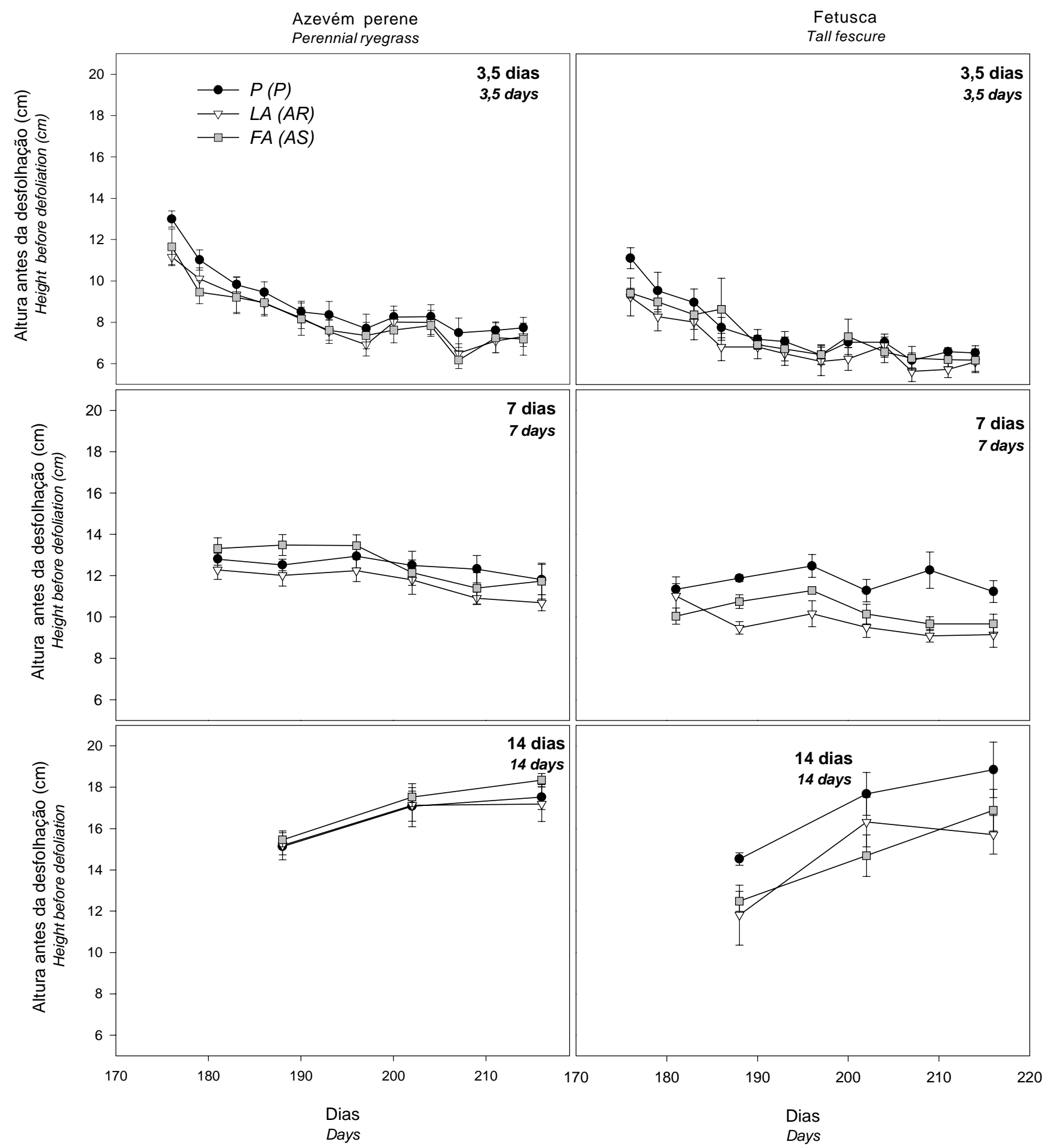

Figura 1 - Evolução da altura do azevém perene e da festuca, durante toda a fase experimental, em função do intervalo de desfolhação $(3,5,7$ e 14 dias) e da distribuição horizontal do pasto: pura (P), linhas alternadas (LA) e faixas alternadas (FA).

Figure 1 - Changes in the surface height of perennial ryegrass and tall fescue during the duration of the experiment, as a function of the defoliation interval (3.5, 7, and 14 days) and of the sward horizontal distribution: pure $(P)$, alternate rows $(A R)$ and the alternate strips (AS). 


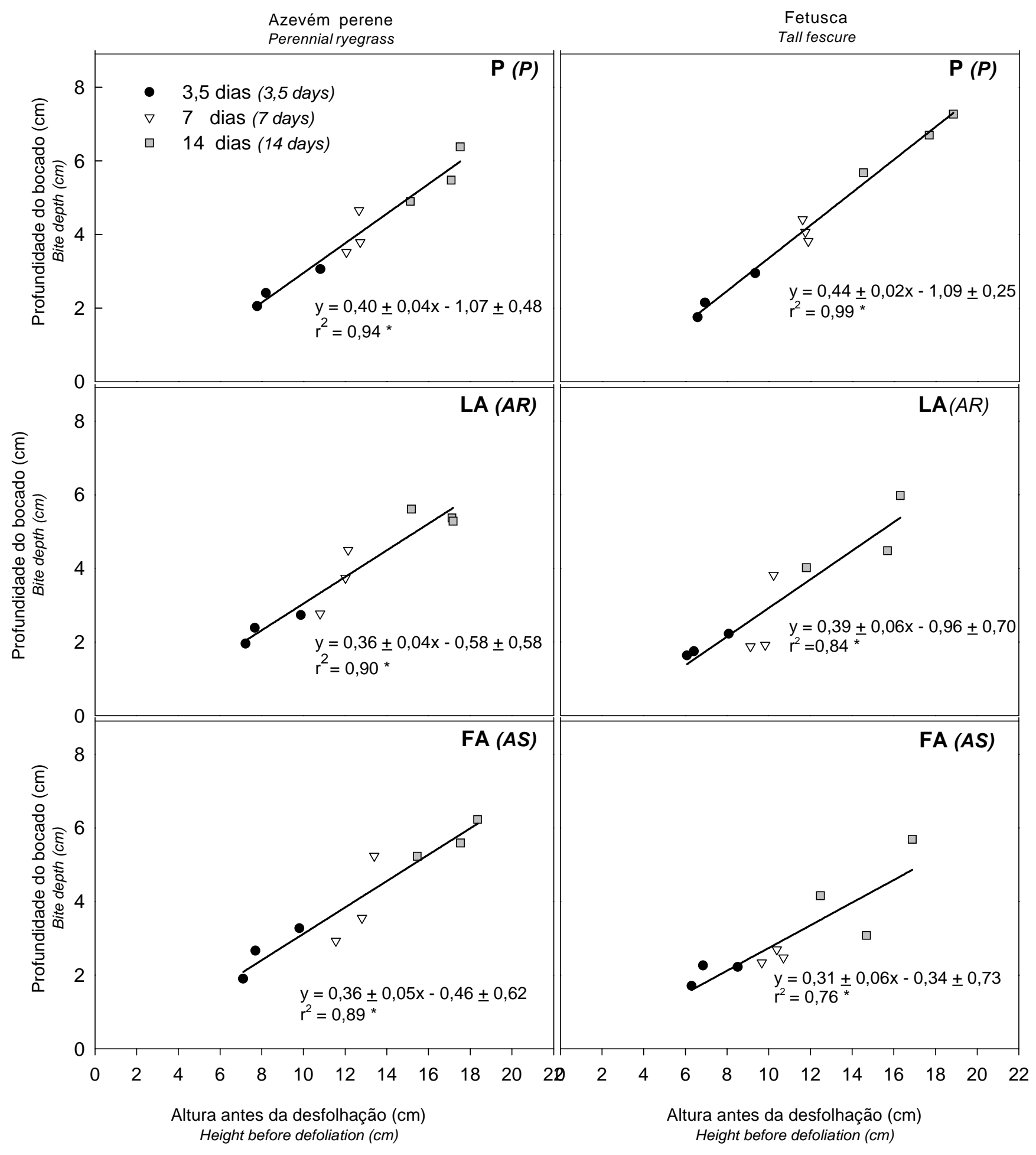

Figura 2 - Efeito do intervalo de desfolhação (3,5, 7 e 14 dias) e da distribuição horizontal do pasto: pura (P), linhas alternadas (LA) e faixas alternadas (FA), na relação entre a altura antes da desfolhação e a profundidade do bocado no azevém perene e na festuca durante todo o período experimental.

Figure 2 - Effect of the defoliation interval (3.5, 7, and 14 days) and of the sward horizontal distribution: pure (P), alternate rows (AR) and the alternate strips (AS), on the relationship between the sward height before defoliation and the bite depth of perennial ryegrass and tall fescue during the all the experiment. 
diminuiu (de $44 \%$ para 39 e $31 \%$, respectivamente, para pura, linhas alternadas e faixas alternadas), sendo assim menos consumida. Na condição de faixas alternadas o menor consumo dessa espécie pode ser devido a sua menor altura em relação ao azevém, uma vez que os animais selecionam os pastos mais altos (Armstrong et al., 1995).

Além disso, a maior profundidade do bocado foi associada a bocados de maior massa. Nos pastos mais altos, gerados por desfolhações menos freqüentes (a cada 7 e 14 dias), a massa do bocado foi de 0,12 e $0,17 \mathrm{~g}$ deMS, respectivamente (Figura 3) e, quando pastejados mais freqüentemente (a cada 3,5 dias), foi reduzida (0,06 g de MS). Nessa condição, provavelmente, a dificuldade na apreensão do material e a diminuição na profundidade do bocado levaram à redução na massa do bocado, tendo em vista que essa variável é função das modificações na área e/ou profundidade do bocado e da densidade de MS no estrato pastejado (Laca et al., 1992; Carvalho, 1997).

\section{Seleção entre espécies}

O processo de desfolhação pode ser influenciado pela distribuição horizontal das plantas, tendo em vista que o animal, diante de uma escolha, pode selecionar plantas e/ou parte das plantas (Tainton et al., 1996). Na distribuição horizontal de faixas alter-

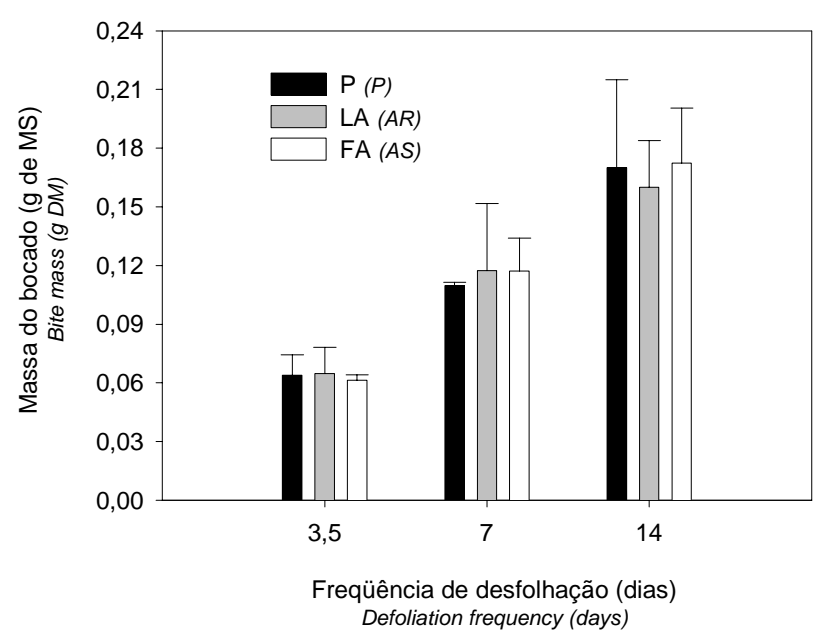

Figura 3 - Efeito do intervalo de desfolhação (3,5, 7 e 14 dias) e da distribuição horizontal do pasto: pura $(P)$, linhas alternadas $(L A)$ e faixas alternadas (FA), na massa do bocado.

Figure 3 - Effects of the defoliation interval (3.5, 7, and 14 days) and of the sward horizontal distribution: pure $(P)$, alternate rows $(A R)$ and the alternate strips (AS) on the bite mass. nadas, onde as espécies estavam dispostas em faixas lado a lado e o grau de mistura entre as espécies era menor, pode-se dizer que a seleção foi facilitada em relação a distribuição em linhas alternadas onde as plantas estavam bem misturadas. Assim, comparou-se a porcentagem de bocados realizados em cada espécie no tratamento de faixas alternadas (Figura 4) e foi constatado que o número de bocados realizados no azevém foi superior $(60 \%)$ ao da festuca $(40 \%)$ quando desfolhado a cada 3,5 e 7 dias. A maior desfolhação no azevém nesses intervalos pode ter ocorrido devido a seleção do azevém e/ou pela menor altura da festuca em relação ao azevém. Porém, no intervalo de desfolhação de 14 dias, embora essa espécie tenha mantido menor altura em relação ao azevém (Figura 1), a porcentagem de bocados foi semelhante.

Taxas de crescimento, senescência, desfolhação e eficiências de utilização

Com relação a distribuição horizontal do pasto, observa-se que em linhas alternadas a taxa de crescimento do azevém foi maior em relação aos demais tratamentos (Tabela 2). Nessa condição, o crescimento da festuca foi pequeno, favorecendo o crescimento do azevém. Além disso, foi observado que a desfolhação do azevém puro é maior do que em

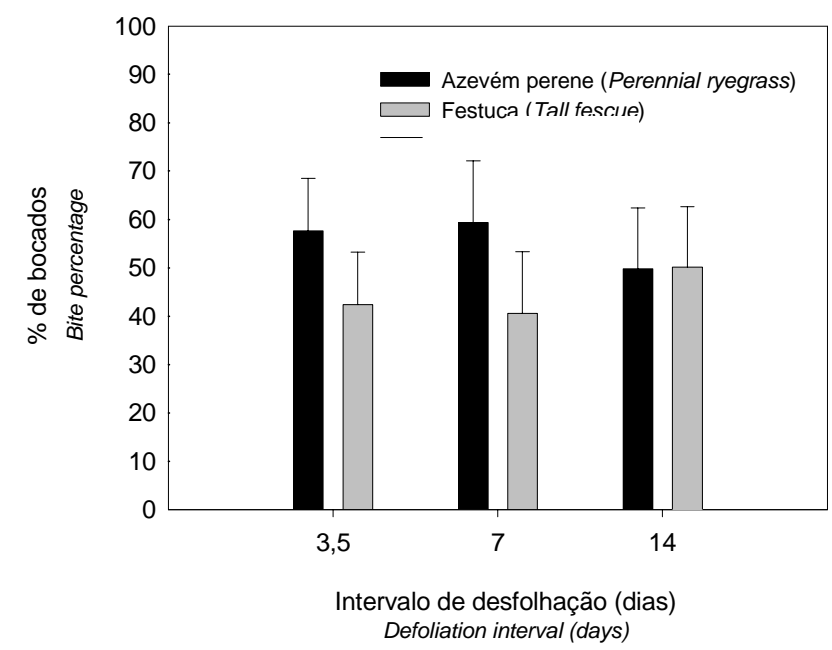

Figura 4 - Efeito do intervalo de desfolhação (3,5, 7 e 14 dias) na porcentagem de bocados realizados no azevém perene e na festuca na distribuição horizontal de faixas alternadas.

Figure 4 - Effects of the defoliation interval (3.5, 7, and 14 days) on the percentage of bites made in perennial ryegrass and in tall fescue in the alternate strips.

R. Bras. Zootec., v.31, n.5, p.1901-1911, 2002 
Tabela 2 - Efeito da distribuição horizontal do pasto: pura (P), linhas alternadas (LA) e faixas alternadas (FA) nas taxas de crescimento, desfolhação e senescência, eficiências real (ERUP) e potencial (EPUP) de utilização do pasto e intervalo real de desfolhação do azevém perene $(A)$ e da festuca $(F)$

Table 2 - Effects of different sward horizontal distribution: pure $(P)$, alternate rows $(A R)$ and alternate strips (AS) on the growth, defoliation and senescence fluxes, on the actual (AEHU) and potential (PEHU) herbage utilisation efficiencies and the tiller defoliation interval of perennial ryegrass $(R)$ and tall fescue $(F)$

\begin{tabular}{|c|c|c|c|c|}
\hline & \multirow[t]{2}{*}{$\begin{array}{l}\text { Espécie } \\
\text { Specie }\end{array}$} & \multicolumn{3}{|c|}{$\begin{array}{c}\text { Distribuição horizontal } \\
\text { Horizontal distribution }\end{array}$} \\
\hline & & $\begin{array}{l}\mathrm{P} \\
P\end{array}$ & $\begin{array}{l}\text { LA } \\
A R\end{array}$ & $\begin{array}{l}\text { FA } \\
A S\end{array}$ \\
\hline Crescimento (g de MS. $\mathrm{m}^{-1}$ ) & $\mathrm{A}(R)$ & $0,57^{\mathrm{Ab}}$ & $0,99^{\mathrm{Aa}}$ & $0,60^{\mathrm{Ab}}$ \\
\hline Growth $\left(\mathrm{g} D M . \mathrm{m}^{-1}\right)$ & $\mathrm{F}(F)$ & $0,31^{\mathrm{Bab}}$ & $0,14^{\mathrm{Bb}}$ & $0,46^{\mathrm{Aa}}$ \\
\hline Desfolhação (g de MS.m-1) & $\mathrm{A}(R)$ & $0,57^{\mathrm{Aa}}$ & $0,49^{\mathrm{Aa}}$ & $0,40^{\mathrm{Aa}}$ \\
\hline Defoliation ( $\mathrm{g}$ DM. $\mathrm{m}^{-1}$ ) & $\mathrm{F}(F)$ & $0,37^{\mathrm{Aa}}$ & $0,08^{\mathrm{Bb}}$ & $0,26^{\mathrm{Aab}}$ \\
\hline Senescência (g de MS.m ${ }^{-1}$ ) & $\mathrm{A}(R)$ & $0,20^{\mathrm{Aa}}$ & $0,32^{\mathrm{Aa}}$ & $0,36^{\mathrm{Aa}}$ \\
\hline Senescence $\left(\mathrm{g} D M . \mathrm{m}^{-1}\right)$ & $\mathrm{F}(F)$ & $0,15^{\mathrm{Aa}}$ & $0,07 \mathrm{Aa}$ & $0,20^{\mathrm{Aa}}$ \\
\hline ERUP & $\mathrm{A}(R)$ & $1,00^{\mathrm{Aa}}$ & $0,49^{\mathrm{Aa}}$ & $0,67^{\mathrm{Aa}}$ \\
\hline$A E H U$ & $\mathrm{~F}(F)$ & $1,19^{\mathrm{Aa}}$ & $0,57^{\mathrm{Aa}}$ & $0,56^{\mathrm{Aa}}$ \\
\hline EPUP & $\mathrm{A}(R)$ & $0,65^{\mathrm{Aa}}$ & $0,68^{\mathrm{Aa}}$ & $0,40^{\mathrm{Aa}}$ \\
\hline PEHU & $\mathrm{F}(F)$ & $0,52^{\mathrm{Aa}}$ & $0,50^{\mathrm{Aa}}$ & $0,56^{\mathrm{Aa}}$ \\
\hline Intervalo real de desfolhação (dias) & $\mathrm{A}(R)$ & $9^{\mathrm{Aa}}$ & $12^{\mathrm{Aa}}$ & $8^{\mathrm{Aa}}$ \\
\hline Defoliation interval (days) & $\mathrm{F}(F)$ & $13^{\mathrm{Aa}}$ & $19^{\mathrm{Aa}}$ & $19^{\mathrm{Aa}}$ \\
\hline
\end{tabular}

Médias seguidas de letras distintas (maiúsculas nas colunas e minúsculas nas linhas) diferem $(p<0,05)$ pelo teste Tukey.

Mean with different letters (high cap columnwise and low cap rowrwise) differ significantly at $p<.05$, according to Tukey multiple range test.

associações, o que indica que mesmo a festuca não sendo a espécie de maior preferência ela é consumida na associação, mesmo que em menor quantidade.

Comparando-se a festuca em faixas alternadas em relação a pastos puros, observa-se que pura essa teve menor crescimento, pois nessa condição, estando como único material, ela foi mais consumida do que quando havia a oferta do azevém (faixas alternadas), condição na qual a taxa de crescimento foi maior, devido a menor desfolhação, ocasionada pela seleção por azevém, como visto anteriormente.

Porém, quando associada em linhas alternadas, as taxas de crescimento e desfolhação foram muito baixas, pois nessa condição a disponibilidade de material era menor, diminuindo a desfolhação, sendo que o menor crescimento pode ser relacionado ao elevado índice de agressividade do azevém (Figura 5), que indica a ocorrência de competição entre as espécies. Além disso, a festuca se manteve em um estrato inferior, portanto protegida da desfolhação, o que pode ser evidenciado pela menor taxa e menor profundidade de desfolhação (Figura 2) e pelo maior intervalo real de desfolhação que, embora as diferenças não tenham sido significativas, foi cerca de 7 dias superior em relação ao azevém.

De acordo com Soussana \& Lafarge (1998) o maior crescimento das plantas proporciona um aumento nas perdas de nutrientes por senescência. No entanto, nesse experimento, não houve variação na taxa de senescência bem como nas eficiências de utilização do pasto (Tabela 2).

Densidade populacional de perfilhos

A densidade populacional de perfilhos do azevém puro foi menor $(\mathrm{p}<0,05)$ do que em associação (Figura 6). Além disso, observa-se que as duas espécies quando puras produziram praticamente o mesmo número de perfilhos. No entanto, em associação o número de perfilhos do azevém foi sempre superior à festuca, sendo essa diferença mais acentuada para o tratamento de linhas alternadas, pois nessa condição o desenvolvimento da festuca foi prejudicado e além disso, como ela se manteve em um estrato inferior, a entrada de luz pode não ter sido suficiente para estimular o perfilhamento uma vez que a qualidade da luz é um dos principais fatores determinantes do perfilhamento (Lemaire \& Chapman, 1996; Mazzanti, 1997; Lemaire, 1999).

A densidade populacional de perfilhos também é função do equilíbrio entre as taxas de aparecimento e morte de perfilhos (Lemaire \& Chapman, 1996) o que explica a diferença entre espécies, pois a maior densidade populacional de perfilhos do azevém está associada à maior taxa de emissão de folhas dessa espécie em relação a festuca (Mazzanti, 1997).

O intervalo de desfolhação não modificou $(p>0,05)$ a densidade populacional de perfilhos do azevém e da 


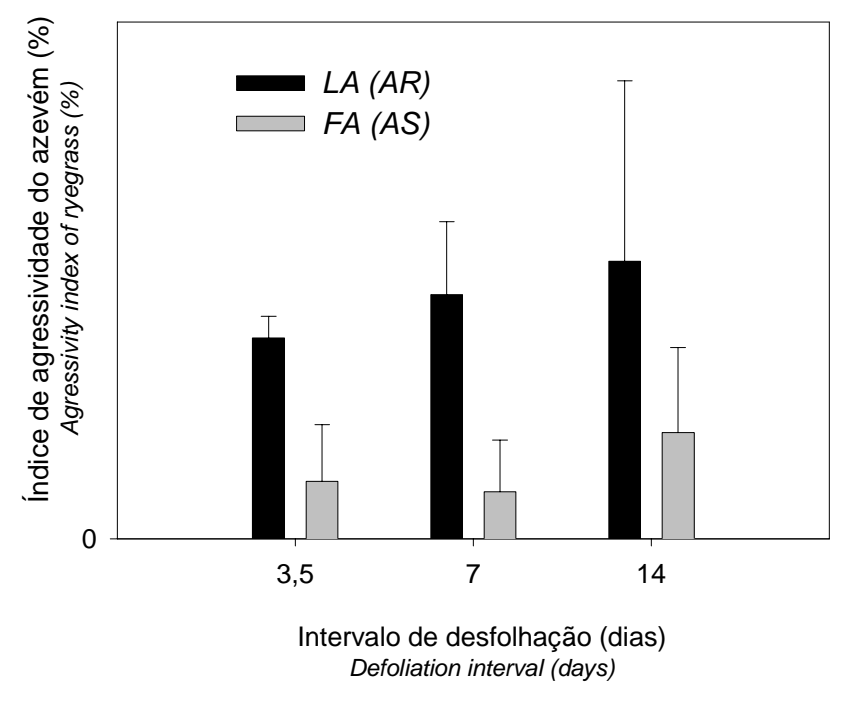

Figura 5 - Efeito do intervalo de desfolhação (3,5, 7 e 14 dias) e da distribuição horizontal de linhas alternadas (LA) e faixas alternadas (FA) no índice de agressividade do azevém perene.

Figure 5 - Effects of the defoliation interval (3.5, 7, and 14 days) and of the sward horizontal distribution: pure $(P)$, alternate rows $(A R)$ and the alternate strips (AS) on the agressivity index of perennial ryegrass.

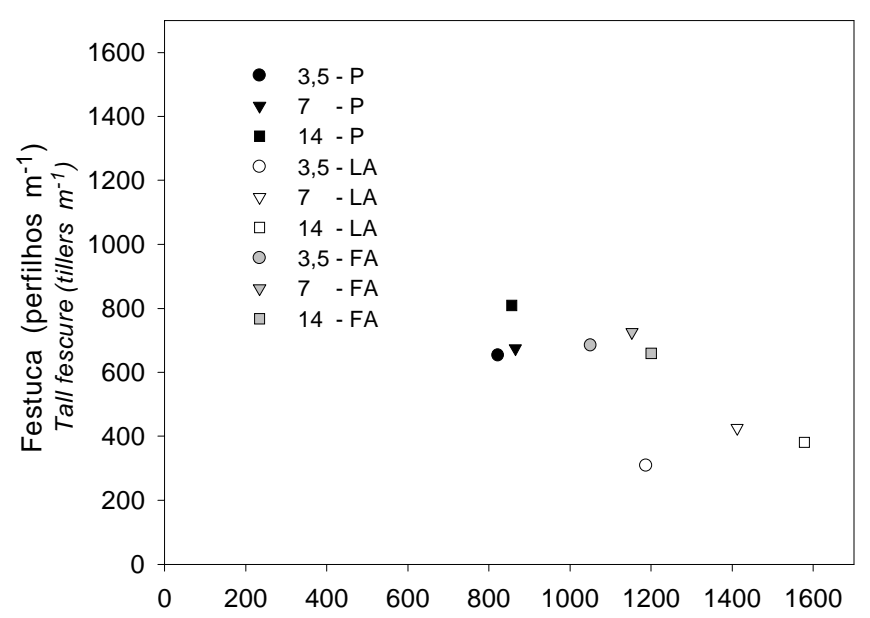

Azevém perene (perfilhos $\mathrm{m}^{-1}$ ) Perennial ryegrass (tillers $m^{-1}$ )

Figura 6 - Efeito do intervalo de desfolhação (3,5, 7 e 14 dias) e da distribuição horizontal do pasto, pura $(P)$, linhas alternadas $(L A)$ e faixas alternadas (FA), na densidade de perfilhos do azevém perene e da festuca.

Figure 6 - Effects of the defoliation interval (3.5, 7, and 14 days) and of the sward horizontal distribution: pure $(P)$, alternate rows $(A R)$ and the alternate strips $(A S)$ on the tiller density of perennial ryegrass and tall fescue. festuca, embora se esperasse que desfolhações mais frequientes, que reduzem a altura do pasto permitindo uma maior entrada de luz nos estratos inferiores, levassem a produção de um maior número de perfilhos (Matthew et al., 1995).

Massa do perfilho e produção de matéria seca

Em intervalos de desfolhação maiores (14 dias), a massa do perfilho (Figura 7) foi maior $(p<0,05)$ resultando assim em uma maior produção de MS (Figura 8) no entanto, nos intervalos de desfolhação menores (3,5 dias), a produção de MS foi menor pois nessas condições a área foliar remanescente manteve-se mais baixa, prejudicando a recuperação da planta após pastejo e resultando na produção de perfilhos de menor peso.

Com relação à massa do perfilho (Figura 7), não houve efeito $(p<0,05)$ da distribuição horizontal do pasto e os resultados foram similares entre espécies quando desfolhadas mais freqüentemente $(3,5$ e 7 dias). No entanto, na associação de linhas alternadas, quando desfolhadas com menor freqüência (14 dias), os perfilhos do azevém tiveram maior massa pois nessa condição a festuca pode ter sido prejudicada pelo sombreamento e elevado índice de agressividade do azevém.

A produção de MS (Figura 8) foi semelhante entre espécies quando essas foram mantidas puras, porém quando em associação, a produção de MS do azevém foi superior à da festuca, principalmente quando distribuída em linhas alternadas, pois nessa condição o elevado índice de agressividade do azevém (Figura 5) levou à menor densidade populacional de perfilhos e menor produção, o que indica que a festuca foi desfavorecida, provavelmente pela competição. Já na distribuição horizontal de faixas alternadas, a massa do perfilho e a produção de MS da festuca foram maiores do que associada em linhas alternadas. Observando-se a Figura 5, nota-se que o índice de agressividade do azevém foi menor, ou seja, o grau de competição foi menor permitindo, dessa forma, que a festuca produzisse perfilhos de maior massa bem como uma maior produção de MS.

Observa-se que não houve efeito do intervalo de desfolhação no índice de agressividade do azevém em linhas alternadas $(0,93)$ e em faixas alternadas $(0,27)$. Da mesma forma, a porcentagem de festuca não foi modificada com a variação do intervalo de desfolhação, ou seja: em torno de 17,5 e $39,9 \%$ para linhas alternadas e faixas alternadas, respectivamente. A baixa porcentagem de festuca na distribuição de

R. Bras. Zootec., v.31, n.5, p.1901-1911, 2002 


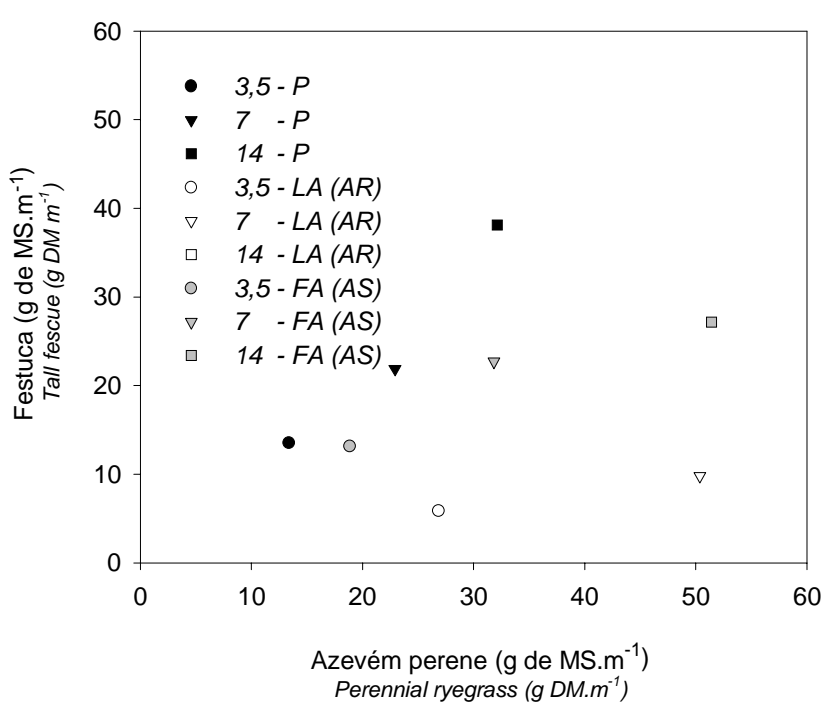

Figura 7 - Efeito do intervalo de desfolhação (3,5, 7 e 14 dias) e da distribuição horizontal do pasto, pura $(P)$, linhas alternadas $(L A)$ e faixas alternadas ( $F A$ ), na massa do perfilho do azevém perene e da festuca.

Figure 7 - Effects of the defoliation interval (3.5, 7, and 14 days) and of the sward horizontal distribution: pure $(P)$, alternate rows $(A R)$ and the alternate strips (AS) on the tiller mass of perennial ryegrass and tall fescue.

Obs.: Tratamento 14 LA dados não avaliados

linhas alternadas está relacionada ao elevado índice de agressividade do azevém nessa condição. Além disso, os cortes realizados a cada 15 dias no período de estabelecimento podem ter prejudicado o estabelecimento dessa espécie, tendo em vista que essa é uma espécie que apresenta menor velocidade de emissão de folhas e o intervalo de desfolhação imposto pode ter sido menor que o período necessário à emissão de uma nova folha. No azevém perene, isso não ocorreu, visto que essa espécie possui velocidade de emissão de folhas mais rápida, adaptando-se, assim, a desfolhações mais freqüentes e de maior intensidade.

\section{Conclusões}

As espécies responderam de forma diferenciada à desfolhação. A festuca associada foi desfolhada em menor intensidade do que quando pura. Em linhas alternadas, essa espécie se manteve mais baixa e com menor crescimento, devido à competição com o azevém e, como conseqüência, manteve-se em um estrato inferior que a protegeu da desfolhação. Porém, quando

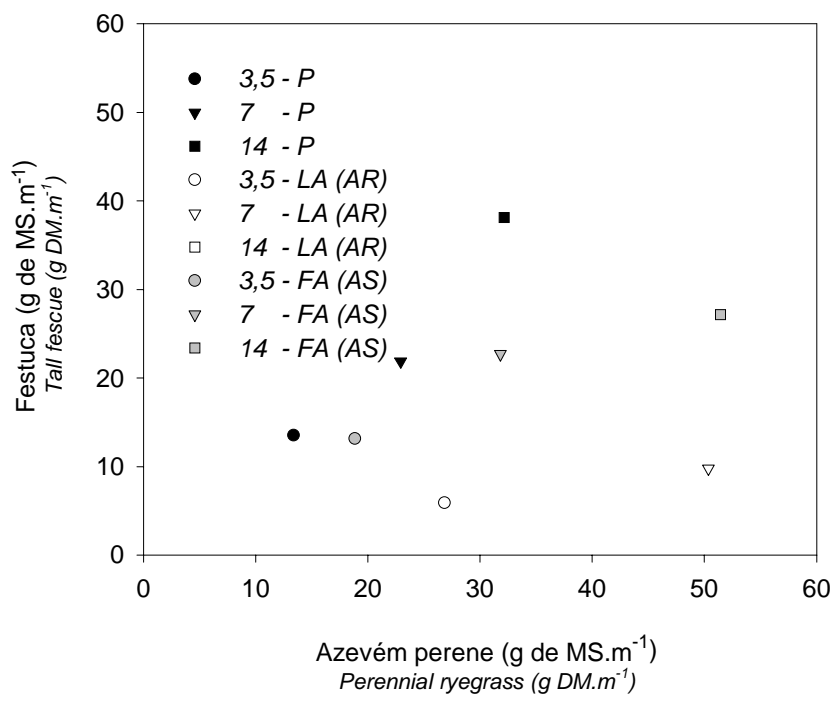

Figura 8 - Efeito do intervalo de desfolhação (3,5, 7 e 14 dias) e da distribuição horizontal do pasto, pura $(P)$, linhas alternadas $(L A)$ e faixas alternadas (FA), na produção de matéria seca do azevém perene e da festuca.

Figure 8 - Effects of the defoliation interval (3.5, 7, and 14 days) and of the sward horizontal distribution: pure $(P)$, alternate rows $(A R)$ and the alternate strips (AS) on the dry matter production of perennial ryegrass and tall fescue.

em faixas alternadas, a menor desfolhação, ocasionada pela seleção do azevém perene, permitiu a maior taxa de crescimento dessa espécie.

A variação no intervalo de desfolhação permitiu que as maiores alturas, geradas por desfolhações menos freqüientes, levassem à realização de bocados mais profundos e de maior massa. Por outro lado, desfolhações mais freqüentes, que mantiveram o pasto mais baixo, reduziram a profundidade e a massa do bocado.

\section{Literatura Citada}

ARMSTRONG, R.H.; ROBERTSON, E.; HUNTER, E.A. The effect of sward height and its direction of change on herbage intake, diet selection and performance on weaned lambs grazing ryegrass swards. Grass and Forage Science, v.50, p.389-398, 1995.

BRISKE, D.D. Developmental morphology and physiology of grasses. In: HEITSCHMIDT, R.K.; STUTH, J.K. (Eds.). Grazing management: an ecological perspective. Portland: Timber Press, 1991. p.85-108.

CARRÈRE, P.; LOUAULT, F.; SOUSSANA, J.F et al. Tissue turnover within grass-clover mixed swards grazed by sheep. Methodology for calculating growth, senescence and intake fluxes. Journal of Applied Ecology, v.34, p.333-348, 1997. 
CARVALHO, P.C.F. A estrutura da pastagem e o comportamento ingestivo de ruminantes em pastejo. In: SIMPÓSIO SOBRE AVALIAÇÃO DE PASTAGENS COM ANIMAIS, 1., 1997, Maringá. Anais... Maringá: 1997. p.25-52.

GORDON, I.J.; LASCANO, C. Foraging strategies of ruminant livestock on intensively managed grassland: potential and constraints. In: INTERNATIONAL GRASSLAND CONGRESS, 17., 1993, Palmerston North. Proceedings... Palmerston North, 1993. p.681-690.

ILLIUS, A.W.; CLARK, D.A.; HODGSON, J. Discrimination and patch choice by sheep grazing grass-clover swards. Journal Animal Ecology, v.61, p.183-194, 1992.

LACA, E.A.; UNGAR, E.D.; SELIGMAN, N.G. et al. An integrated methodology for studying short-term grazing behavior of cattle. Grass and Forage Science, v.47, p.91-102, 1992.

LEMAIRE, G. Les flux de tissus foliaires au sein des peuplements prairiaux. eléments pour une conduite raisonnée du pâturage. Fourrages, v.159, p.203-222, 1999.

LEMAIRE, G.; CHAPMAN, D. Tissue flows in grazed plant communities. In: HODGSON, J.; ILLIUS, A.W. (Eds.). The ecology and management of grazing systems. New Zealand: CAB International, 1996. p.3-35.

LOUAULT, F.; CARRÈRE, P.; SOUSSANA, J.F. Grass and clover herbage use efficiencies in mixtures continuously grazed by sheep. Grass and Forage Science, v.52, p.388-400, 1997.

MATTHEW, C.; LEMAIRE, G.; SACKVILLE HAMILTON, N.R. et al. A modified self-thinning equation to describe size/ density relationships for defoliated swards. Annals of Botany, v.76, p.579-587, 1995.
MAZZANTI, A. Adaptación de especies forrajeras a la defoliación. In: SIMPÓSIO SOBRE AVALIAÇÃO DE PASTAGENS COM ANIMAIS, 1., 1997, Maringá. Anais... Maringá: 1997. p.75-84.

McGILHRIST, C.A.; TRENBATH, B.R. A revised analysis of plant competition experiments. Biometrics, v.27, p.659671, 1971.

SOUSSANA, J.F.; LAFARGE, M. Competition for resources between neighbouring species and patch scale vegetation dynamics in temperate grasslands. Annales de Zootechnie, v.47, p.371-382, 1998.

TAINTON, N.M.; MORRIS C.D.; HARDY, M.B Complexity and stability in grazing systems. In: HODGSON J.; ILLIUS, A.W. (Eds.). The ecology and management of grazing systems. Wallingford UK: CAB International, 1996. p.275-299.

WADE, M.H. Factors affecting the availability of vegetative Lolium perenne to grazing dairy cows with special reference to sward characteristics stoking rate and grazing method. Rennes: Université de Rennes, 1991. 70p. Thèse de Doctorat - Université de Rennes, 1991. 